\title{
Dissimilar occupations and marital stability
}

\author{
Ben Van Kammen ${ }^{1 *}$ and Scott J Adams ${ }^{2}$
}

\author{
* Correspondence: bvankamm@ \\ purdue.edu \\ ${ }^{1}$ Economics Department, Purdue \\ University, 4043 W. State Street, \\ Room 531, West Lafayette, IN 47907, \\ USA \\ Full list of author information is \\ available at the end of the article
}

\begin{abstract}
We show that information revealed by the occupation choices of spouses predicts marital dissolution. Using a novel measure of occupational distance constructed from the $\mathrm{O}^{*}$ Net Content Model, we find that spouses more closely matched in terms of their occupations' requisite knowledge are more likely to divorce. This supports the hypothesis that gains from division of labor within a household can render a marriage more durable. On the other hand, spouses that are dissimilar in terms of their occupations' activities are more likely to divorce. This suggests that each spouse brings an inclination toward certain activities to the marriage that reflects compatible preferences for joint consumption of household public goods.
\end{abstract}

JEL codes: D13; J12; J24

Keywords: Spousal matching; Marital stability; PSID; O*Net; Gains from marriage

'Baby ain't it somethin' how we lasted this long; you and me provin' everyone wrong; don't think we'll ever get our differences patched; don't really matter cuz we're perfectly matched."

- Leiber (1990), performed by Paula Abdul and MC Skat Kat

\section{Introduction}

Previous research finds that the rise of dual-earner households is highly correlated with rising divorce rates, with ample evidence supporting causality in both directions [e.g., (Johnson \& Skinner, 1986), (Spitze \& South, 1985), (Bremmer \& Kesselring, 2004), (Ging \& Kim, 2011)]. Conditional on both spouses working, however, the determinants of a successful marriage are complex ${ }^{1}$. In this paper, we use a novel approach that considers information revealed through current and past occupation choices in an empirical model of the predictors of a successful (or unsuccessful) marriage, as measured by divorce. We propose that the type of job one chooses, and the relative distance from their spouse's job in terms of job content, reveals much about gains form specialization and relative preferences for household goods, which, in turn affects marital stability. Our use of occupation data to reveal information about spousal skills and preferences builds on a wide range of research that has shown a correlation between underlying individual traits, both cognitive and non-cognitive, and occupational choice ${ }^{2}$.

Although our paper is related to the previous literature that considers marriages in the context of relative wages and schooling of the spouses [e.g., (Lam, 1988) and (Liu \& Lu, 2006)], we eschew rank-order or vertical comparisons of spouses in this paper. We 
instead posit a "horizontal" comparison of spousal characteristics with no necessary ordinal significance. Our variables of interest measure dissimilarity between spouses' occupations on a number of dimensions, which take the form of "distance" measures. Therefore, they act like cartographic distances in that they do not convey which endpoint is at higher elevation or latitude. Consequently, these occupation measures can test theories of marital stability that are either based on similarities of preferences for household goods or dissimilarities allowing for gains from specialization. Spousal contrasts can be either good or bad for a marriage, depending upon which dimensions of the occupations the distance measures are based.

Our evidence suggests that there are two dimensions of occupation distance that relate to marital stability and dissolution. First, spouses whose occupational information reveals dissimilarity in terms of knowledge are less likely to divorce or separate. The knowledge-based distance measures most likely capture what the spouses will be able to produce within the household given the knowledge that each spouse's occupation requires. This supports the prediction that households that can divide tasks based on comparative advantage will be more stable. Second, spouses that are dissimilar in terms of vocational activities are more likely to divorce. The activities involved in one's chosen occupation reveal preferences for activities more generally. To the extent that couples share activities and consume household public goods, one's preferences for activities can be more or less compatible with a spouse's preferences.

We extend this analysis to single-earner households as well. As with the literature on wage sorting among couples, this research must overcome the obstacle of missing data-namely from spouses that are not earning a wage and have no current occupation from which to measure distance. Our approach overcomes this using longitudinal data observing individuals' earlier occupations. A "synthetic" distance predicted from characteristics of the spouses is also used as a robustness check. Combining information gleaned from current occupations, earlier occupations, and synthetic distances demonstrates that spouses' joint choices of occupations explains marital stability, i.e., divorce behavior. Moreover, the effects of distance measures on divorce probability are evident among single and dual earner households, among the sub sample of households in which neither spouse has changed occupations since marriage, and are robust to all of these methods for treating missing data on single earners.

The paper does not make causal claims about occupations and divorce, since our model does not simulate random assignment to jobs or spouses, but it is defensible that occupational dissimilarity measures contain information orthogonal to the other factors that might influence the labor force participation-marital stability relationship. Our results should be read as adding explanatory power to empirical divorce models, with the correlations signed as theory predicts.

The paper proceeds as follows. Section 2 reviews the existing literature on marital dissolution, as well as the related literature on spousal matching. Section 3 discusses the construction of occupational distance measures. Section 4 discusses the data and methods used in the present examination of marriage and marital dissolution, and the empirical results are presented and discussed in Section 5. Section 6 concludes. 


\section{Background and conceptual framework}

\subsection{Related literature on the strength of spousal matches}

The framework for analyzing formation and dissolution of marriage originates with Becker (1973, 1974), who describes the household production function with members' time and market goods as inputs. Becker speculates that the returns to scale of the production function are increasing, generating the incentives to marry, and the gains are magnified if one spouse concentrates on wage earning (providing market goods) and the other spouse concentrates on direct home production. Among the many extensions of this basic model is Weiss (1997), who relies on credit constraints to explain the same sorting mechanism. Specifically the gain from marriage comes from the spouse with lower wage-earning potential financing human capital investments for the spouse with higher wage-earning potential. The high potential spouse could not otherwise invest in this manner because of constraints on borrowing against future income. Weiss (p. 86) shows that this gain in future income comes from specialization. Thus, two spouses with equal earning ability do not benefit from marrying one another. These models imply that the optimal pattern for pairing husbands and wives is negative sorting on wages-since it maximizes the gains from specialization (see Becker 1973, 826-828).

Sorting according to labor market productivity need not be the extent of the husband-wife matching mechanism. Mitigating spouses' earnings risks is another source of gains from marriage, but without obvious implications for how spouses sort in terms of productivity level. If each spouse faces uncertainty about the income he or she will earn, having another person in the household to insure against idiosyncratic earnings shocks makes both spouses' expected utilities higher. Naturally the advantage of such insurance is more limited as the correlation of earnings risk between spouses grows. The implication is that dissimilar occupations or industries will more effectively mitigate the risk to household consumption from earnings instability. According to the risk-sharing theory, marriages between "dissimilarly employed" spouses generate more gains. We note that dissimilar, here, does not imply an ordinal ranking. We simply mean that diversification of jobs is good in terms of ensuring some income for the household.

There are several other reasons to suspect that dissimilar spousal occupations affect match strength. Lich-Tyler (2003) shows how assortative matching is based on similar preferences for household public goods in the absence of differences in skills, wages, etc. Weiss and Willis (1997) found the same basic notion holds with respect to education. Specifically the marginal effect of an interaction term consisting of husband's and wife's education decreases the probability of divorce. The authors interpret this as the result of preference complementarity and shared consumption (p. 316). From this literature, we postulate that preferences for goods correlate with individuals' choices of occupation. Non-wage amenities and disamenities attract individuals to occupations based on their valuations of the amenities. It is reasonable to expect, for example, two people who chose to work an outdoor job to also enjoy outdoor leisure activities.

Regardless of whether preferences and labor market traits are correlated, marriage generates gains for the spouses if non-rival household goods are consumed since any amount of the good consumed by one partner generates utility for the other partner. Lam (1988) elaborates on this possibility by exploring two consequences of a household public good-correlation in preferences for the public good and home 
production of the public good. The first suggests positive (e.g., outdoor work and outdoor leisure) sorting of spouses, and the second suggests negative (specializationbased) sorting. The latter depends on the public good's production function and how complementary the spouses' time inputs are in terms of allowing for specialization.

The novel approach of our paper is to use information on occupations to learn more about spousal compatibility. Given that there is ample evidence from the previous literature that both similarities and dissimilarities draw spouses together and make marriages work, we suspect the richness of information about one's occupation can shed light on the role of dissimilarities. The risk sharing explanations for match quality and the idea that dissimilar spouses could more effectively divide tasks in the household imply that spouses with proximal occupations reap fewer gains from marriage. Alternatively spouses with occupations that are dissimilar could have a disadvantage in match quality if the gains from marriage come from preference compatibility, complementarity in household public good production, or spillover of human capital within the household. The last idea, suggested by Benham (1974), argues that one spouse's earnings are enhanced by the knowledge of the other spouse, assuming that the other spouse has relevant knowledge. This would be applicable when both spouses' occupations are complements in market goods production (e.g., physician and nurse). A marriage involving two such occupations could be expected to make both spouses better at doing their individual jobs, thus generating larger gains from marriage.

\subsection{Additional factors explaining marital dissolution}

As with most papers in the literature, our aim is to measure match quality but must use divorce or separation as a proxy. This relies on the assumption that poorer match quality renders divorce more likely. Spouses gain information during the marriage about its quality and the availability of better matches (there may also be some "on the job search"). Since dissolution is costly, minor adverse realizations do not compel wellmatched spouses to divorce; only marginally-well-matched couples do. The question we ask in this paper then is: are couples with more distant occupations more likely or less likely to be marginally-well-matched (ceteris paribus)? Since we use divorce and separation to reveal marriages that are relatively poor matches, we appeal to the existing literature on marital dissolution to identify other factors that are important to include in the analysis as controls. Weiss and Willis (1997) find that shocks to the earnings of one spouse affect the probability of divorce. Such increases to the husband's earnings stabilize the marriage while positive shocks to the wife's earnings destabilize it. We interpret this result as suggesting that an increase to the higher-earning spouse stabilizes the marriage, but an increase to the lower-earning spouse destabilizes the marriage. Kalmijn et al. (2007) show that among Dutch couples, the stabilizing effect of income growth for the higher earner is confirmed-but only when the higher earner is male. In households in which the dominant earner is female-growth of the wife's relative income has a destabilizing effect on the marriage. Similarity in the levels of the spouses' schooling at the time of marriage also stabilizes the match, as do higher age at marriage, duration, children, and marital assets like property. Investments in human capital after marriage have mixed consequences for marital stability. They increase the 
earning potential of the household but do so at the expense of household production. Moreover, the additional human capital stock provides the spouse that invests more attractive outside options (Johnson \& Skinner, 1986).

Demographic variables indicating the spouses' religious homogamy significantly predict a lower probability of divorce (Charles \& Stephens, 2004). In a CDC study (Bramlett \& Mosher, 2002), ethnic homogamy, the wife being older than the husband, and successful parental marriages do likewise. Pre-marital cohabitation and previous marriages are positively correlated with divorce probabilities in the Bramlett and Mosher CDC report as well as in other samples (Weiss \& Willis, 1997, pp. 313-15). Living in an area with high male unemployment, a greater proportion in poverty, a higher proportion receiving welfare, and lower median income each predicts higher divorce probability, according to the same CDC study, as does the race of the wife. Lehrer (2008) uses the same data (the National Survey of Family Growth) set to confirm that age-at-marriage is positively related to stability.

Job displacement, particularly layoffs (as opposed to plant closures), adversely affects marital stability (Charles \& Stephens, 2004). This finding has been confirmed for unemployment of husbands using Danish data (Jensen \& Smith, 1990). Geographical movement also tends to destabilize marriages because the motive is usually a new job for one spouse and this tends to benefit that spouse more than the other (Boyle et al. 2008). In Norwegian households, receipt of public transfers, particularly through the wife, increases the likelihood of divorce (Tjotta \& Vaage, 2008). Blackburn (2003) finds that this phenomenon is unrelated to the generosity of welfare programs for single mothers as welfare programs for single mothers do not incentivize divorce for women. Finally, living in an area with greater availability of other mates increases the probability of divorce (South \& Lloyd, 1995) as does working in an occupation with greater availability of other mates (McKinnish, 2007). This literature guides our choice of covariates in regressions.

\section{Measuring the distance between any two occupations}

The innovation in this paper is the construction of a measure of occupational distance that can be used on pairs of spouses to test various theories of marriage. The information for measuring occupational proximity comes from the O"Net Content Model: "The O*NET database contains several hundred variables that represent descriptors of work and worker characteristics, including skill requirements" (O*Net, 2011). The activities, abilities, knowledge and skills files contain the variables we use to measure distance between occupations ${ }^{3}$. Version (16.0) of the database from O*Net consists of scores, from worker and occupational expert questionnaires, assessing the relevance of the various activities, abilities, knowledge, and skills to each occupation ${ }^{4}$.

Relevance is measured on two (ordinal) scales for each occupational dimension: importance ( 1 to 5 ) and level ( 0 to 7 ). The importance scale is accompanied by typical linear, numeric scale language, such as "not important" and "extremely important". The level scale is accompanied by "anchors" that communicate what constitutes a minimal level of performance and what constitutes a sophisticated level. For example, the anchors for ability code, "1.A.2.b.2: Multi-limb Coordination" are shown below.

Level 2 Anchor: "Row a boat"

Level 4 Anchor: "Operate a forklift truck in a warehouse" 
Level 6 Anchor: "Play the drum set in a jazz band"

The ordinal nature of these data poses a practical problem, and so does the existence of two scales per variable. One might worry that the average of the scores among respondents from an occupation is meaningless except in comparison to averages for that occupation on other dimensions-or to other occupations' averages on the same dimension. A few features of the scores ameliorate this problem, however.

1. A dimension on which the average respondent in an occupation scores higher than another dimension can be regarded as more important (at a more sophisticated level) to the occupation.

2. An occupation in which the average respondent scores a dimension higher than the average respondent from another occupation can be regarded as more important (higher level) to the occupation with the higher average score.

Together these features, along with a ranking of each occupation on each dimension, make it possible to compare a pair of occupations according to their places in the distributions of the various O*Net dimensions. Following this premise, we construct measures of the distance between each pair of occupations based on rank, as well as the raw scores. Although the results reported in the paper use the distances based on raw scores, the results are robust to using the rank-based distances as well.

The second problem we confront is the existence of two scales per variable. There are two distinct, yet consequentially similar, options for treating them: 1) treat importance scores as separate dimensions or 2) treat them as weights. The two (in the Euclidian sense) distance measures that result from these options are calculated as follow.

$$
\begin{aligned}
& \text { dist }^{i j}=\left[\sum_{k \in K}\left(A^{i k}-A^{j k}\right)^{2}\right]^{\frac{1}{2}} K \text { includes all level and importance scores. } \\
& \text { dist }_{\text {importance weights }}{ }_{i j}=\left[\sum_{k \in K} W^{i k} W^{j k}\left(A^{i k}-A^{j k}\right)^{2}\right]^{\frac{1}{2}}
\end{aligned}
$$

where, $W^{i k}=\frac{I M P^{i k}}{\sum_{k \in K}^{I M P^{i k}}} K$ includes only level scores.

We prefer the second formula, which uses the relative importance scores as weights, because it distinguishes between level and importance. Instead of counting all level and importance scores equally, the weighted version counts level scores that are important to both occupations heavily and those that are unimportant (to at least one) only slightly. Only if the two occupations differ on important characteristics will they be measured as "far away" by this measure, whereas unimportant differences could result in an overstatement of the distance as measured in number 1. Consequently this paper employs the second (importance weights) calculation of distance between occupations. Once again, however, we have estimated the divorce model using non-importanceweighted distances and the estimates are robust to this.

There are four O*Net files utilized in the preceding exercise: abilities, activities, skills, knowledge. A distance measure can be calculated for each of the four-as well as an "overall" measure. The usefulness inheres in evaluating the proximity of any pair of 
occupations' skill, ability, knowledge, and activity sets. We calculate them for every pair of occupations-as defined in the 2000 Census classification scheme. Then the measures can be matched to observed pairs of occupations (one per spouse) in any household-level micro data including spousal pairs.

\section{Data and methods}

\subsection{Data}

The household-level data in which we observe marriages dissolve or succeed come from the 2003, 2005, and 2007 waves of the PSID (Panel Study of Income Dynamics public use dataset 2003-2007). Consecutive observations of each household provide married couples' characteristics and their marital status 2 years later. A binary ("remain married" equals 0) variable for marital status in the future period is the dependent variable ${ }^{5}$. Our sample consists of couples that are married in the current period and in which at least one reports an occupation.

The PSID contains a wealth of control variables as well; nearly all of the correlates of divorce found in earlier literature are available (or can be imputed). There are 4142 observations of married dual-earning couples in the pooled sample (those married in 2003, 2005 or both) and 1070 observations in which just one spouse works. Table 1 reports summary statistics for relevant variables from the 2003 wave.

There are a few limitations that we face when constructing control variables that are noteworthy in comparison with the rest of the literature. We do not explicitly observe pre-marital cohabitation in the sample. Also the survey only asks about marital status of the parents of the head of the household and not the spouse. So we only observe whether one of the spouses has parents that remained married during childhood. Variables indicating the receipt of Temporary Assistance to Needy Families (TANF), and "other welfare" exist in the PSID, but a very small number of respondents (18) report receiving any welfare. We have not included these variables because of the trivial extent to which they vary.

\subsection{Methods}

The empirical methods and notation follow Charles and Stephens (2004, pp. 496-97) and Weiss and Willis (1997) closely. A couple's separation hazard at a given time, conditional on having remained married as long as they have, depends on the gain in utility they get when married compared to dissolution (net of costs): With $V_{t}$ representing utility from marital in year $t$,

$$
\begin{aligned}
V_{t}= & G(\text { spouses' inputs }(t))+\beta E_{t}\left\{\max \left[V_{t+1}, \text { net utility }(t+1) \mid \text { singletons }\right]\right\} \\
& +\left(\mu_{i}+\varepsilon_{i t}\right)-\text { net utility }(t) \mid \text { singletons. }
\end{aligned}
$$

The utility consists of the value of marriage, in three parts: present household utility $(G)$, an expectation of future utility, and a stochastic part, expressed net of the opportunity cost of marriage. Spouses remain married when the utility is positive and dissolve the marriage otherwise. In our paper, the objects of interest are variables in the match-fixed ("quality") effect, $\mu_{i}$, which makes the gains larger and the match less likely to dissolve. Under Charles's and Stephens's assumptions, the separation hazard $(S)$ is a 
Table 1 Summary statistics of key variables

\begin{tabular}{|c|c|c|c|c|c|c|}
\hline \multirow[b]{2}{*}{ Variable } & \multicolumn{2}{|c|}{ Pooled } & \multicolumn{2}{|c|}{ One earners } & \multicolumn{2}{|c|}{ Two earners } \\
\hline & Mean & S.D. & Mean & S.D. & Mean & S.D. \\
\hline Distance bw Spouses' Occupations 'Abilities' File & - & - & - & - & 0.123 & 0.050 \\
\hline Distance bw Spouses' Occupations 'Activities' File & - & - & - & - & 0.196 & 0.071 \\
\hline Distance bw Spouses' Occupations 'Skills' File & - & - & - & - & 0.159 & 0.067 \\
\hline Distance bw Spouses' Occupations 'Knowledge' File & - & - & - & - & 0.270 & 0.093 \\
\hline |Age(Male)-Age(Female)| & 3.488 & 3.541 & 3.648 & 3.781 & 3.447 & 3.477 \\
\hline Years Married (Imputed) & 15.111 & 12.019 & 20.116 & 14.576 & 13.840 & 10.922 \\
\hline Age of Man When Married & 29.270 & 8.917 & 29.153 & 10.006 & 29.300 & 8.621 \\
\hline Age of Woman When Married & 27.082 & 8.241 & 26.913 & 9.073 & 27.125 & 8.018 \\
\hline Female is Older Than Male $(=1)$ & 0.202 & 0.401 & 0.215 & 0.411 & 0.199 & 0.399 \\
\hline Spouses are same religion $(=1)$ & 0.766 & 0.423 & 0.799 & 0.401 & 0.758 & 0.429 \\
\hline Husband is white & 0.715 & 0.451 & 0.725 & 0.447 & 0.713 & 0.453 \\
\hline Husband is black & 0.195 & 0.396 & 0.174 & 0.380 & 0.200 & 0.400 \\
\hline Wife is white & 0.726 & 0.446 & 0.733 & 0.443 & 0.724 & 0.447 \\
\hline Wife is black & 0.190 & 0.392 & 0.176 & 0.381 & 0.194 & 0.395 \\
\hline Spouses are same race $(=1)$ & 0.940 & 0.238 & 0.950 & 0.219 & 0.937 & 0.243 \\
\hline Head's Parents Intact $(=1)$ & 0.784 & 0.412 & 0.793 & 0.406 & 0.782 & 0.413 \\
\hline Years Education Head & 13.396 & 2.625 & 13.168 & 2.901 & 13.454 & 2.548 \\
\hline Years Education Spouse & 13.452 & 2.452 & 13.133 & 2.555 & 13.533 & 2.420 \\
\hline |Education(Head)-Education(Spouse)| & 1.513 & 1.632 & 1.563 & 1.605 & 1.500 & 1.639 \\
\hline Product of HHs and Wife's Yrs Educ & 184.180 & 57.460 & 177.896 & 62.081 & 185.777 & 56.130 \\
\hline Male Spouse's earnings in $1000 \mathrm{~s}$ & 50.261 & 102.447 & 54.941 & 169.437 & 49.072 & 76.637 \\
\hline Female Spouse's earnings in 1000 s & 23.650 & 24.963 & 7.357 & 24.370 & 27.790 & 23.372 \\
\hline Female Spouse earns more $==1$ & 0.270 & 0.444 & 0.228 & 0.420 & 0.281 & 0.449 \\
\hline City Pop. $>=500 \mathrm{k}$ & 0.140 & 0.347 & 0.132 & 0.338 & 0.142 & 0.349 \\
\hline 100 k < City Pop. $<500$ k & 0.253 & 0.435 & 0.236 & 0.425 & 0.257 & 0.437 \\
\hline 50 k < City Pop. $<100$ k & 0.114 & 0.317 & 0.110 & 0.314 & 0.114 & 0.318 \\
\hline 25 k < City Pop. $<50$ k & 0.130 & 0.337 & 0.130 & 0.336 & 0.131 & 0.337 \\
\hline 10 k < City Pop. $<25$ k & 0.171 & 0.377 & 0.199 & 0.400 & 0.164 & 0.370 \\
\hline $1 \mathrm{Kid}$ & 0.219 & 0.414 & 0.166 & 0.373 & 0.233 & 0.423 \\
\hline 2 Kids & 0.239 & 0.426 & 0.230 & 0.421 & 0.241 & 0.428 \\
\hline 3 Kids & 0.082 & 0.274 & 0.077 & 0.267 & 0.083 & 0.276 \\
\hline 4 Kids & 0.024 & 0.152 & 0.044 & 0.206 & 0.018 & 0.134 \\
\hline 5 or More Kids & 0.007 & 0.086 & 0.012 & 0.107 & 0.006 & 0.080 \\
\hline Owns Home & 0.821 & 0.384 & 0.818 & 0.386 & 0.821 & 0.383 \\
\hline Have Consumer or Student Debt $(=1)$ & 0.572 & 0.495 & 0.470 & 0.500 & 0.598 & 0.491 \\
\hline Contributed to IRA or Pvt. Annuity (=1) & 0.207 & 0.405 & 0.190 & 0.392 & 0.212 & 0.409 \\
\hline Exactly one spouse smokes $(=1)$ & 0.182 & 0.386 & 0.195 & 0.397 & 0.179 & 0.383 \\
\hline Moved last year(=1) & 0.267 & 0.442 & 0.215 & 0.411 & 0.280 & 0.449 \\
\hline Variance of Husband's Occupation Earnings & - & - & - & - & 0.749 & 2.240 \\
\hline Variance of Wife's Occupation Earnings & - & - & - & - & 0.592 & 1.521 \\
\hline Earnings Covariance (Pair of Occupations) & - & - & - & - & 0.054 & 0.777 \\
\hline Head Married > Once $(=1)$ & 0.254 & 0.435 & 0.275 & 0.447 & 0.248 & 0.432 \\
\hline Spouses Employed Same Industry (=1) & - & - & - & - & 0.114 & 0.317 \\
\hline
\end{tabular}


Table 1 Summary statistics of key variables (Continued)

\begin{tabular}{lccc}
\hline Sample size & 2606 & 535 & 2071 \\
\hline The sample summarized in this table is the 2003 cross-section of the PSID. & &
\end{tabular}

linear function $(g)$ of the duration of the marriage, the characteristics of the spouses, and the match-fixed effects:

$$
S_{i t}=g\left[\text { duration }_{i t}, \text { spousal inputs }_{i t}, \text { opportunity costs }_{i t}, \text { match quality }_{i}\right],
$$

where $\left(\frac{\partial S_{i t}}{\partial \mu_{i}}<0\right)$, and the effects can be estimated using a probit model:

$$
\operatorname{Pr}\left(y=y_{j} \mid X\right)=f[\Phi(X \beta)]
$$

In equation (5), $f$ is the probit function and $y_{j} \in\{0,1\}$. The outcome variable, y, equals 1 if the couple is separated or divorced; it equals 0 if they remain married. $\mathrm{X}$ is the vector of explanatory variables listed in Table 1. Charles and Stephens and Weiss and Willis attempted to estimate the match-fixed effects, but their main focus was on earnings shocks. We are directly interested in measures of match-specific quality in this paper, however. The previous studies used variables such as demographic and educational homogamy to capture match-fixed effects. The present paper can be viewed as moving this literature a step forward by incorporating additional match-quality measures based on heterogamy in X, specifically measured through the spouses' occupations.

The danger in relying on dissimilarity measures based on the spouses' occupations is that features of the occupations, themselves, factor into the marital value function. Specifically occupational characteristics may contribute directly to household utility (1st term in (3)), and they may also reveal the value of a spouse's outside options (last term in (3)). For this reason two sets (husband and wife) of indicators for the spouses' occupations are included in the models we estimate. Additionally the information embodied in our distance measures could be related to the variability and co-variability of occupational earnings. These should not be confused with measurements of match quality, which is how we would like to interpret the effects of the distance measures. Consequently measures of each spouse's occupation's (intertemporal real) earnings variance and the pairwise covariance are included in the model to control for any link between the O*Net distances and correlated earnings. The March CPS (1971-2012) is used to calculate the variances and covariance statistics (King, et al. 2012) ${ }^{6}$.

We estimate $\beta$ in the probit equation (5), calculating marginal effects for the distance measures from the estimates. The estimated marginal effects show whether having dissimilar occupations is bad for marital stability. As Table 2 shows, the 4 files' distance measures are not pairwise collinear, and we can estimate distinct effects of Knowledge distance and Activities distance, for example. Since the data include multiple (2003 and 2005) observations of the same households, all standard errors reported are calculated based on clusters for each household. All marginal effects reported are with respect to the probability of dissolution, i.e., positive effects are destabilizing. 
Table 2 Summary statistics for and correlation measures among distance measures

\begin{tabular}{lccccc}
\hline \multicolumn{5}{c}{ Summary statistics } \\
\hline Distance measure & Number combinations & Mean & Standard deviation & Minimum & Maximum \\
\hline Abilities & 126,253 & 0.1416 & 0.0527 & 0 & 0.4168 \\
Activities & 126,253 & 0.2217 & 0.0708 & 0 & 0.5679 \\
Knowledge & 126,253 & 0.1796 & 0.0694 & 0 & 0.5766 \\
Skills & 126,253 & 0.3014 & 0.0831 & 0 & 0.6630 \\
Overall & 126,253 & 0.4438 & 0.1218 & 0 & 1.0070 \\
& & Correlation structure & & \\
Distance measure & Abilities & Activities & Knowledge & Skills & Overall \\
Abilities & 1.000 & & & & \\
Activities & 0.701 & 1.000 & & & \\
Knowledge & 0.803 & 0.761 & 1.000 & 1.000 & \\
Skills & 0.590 & 0.647 & 0.656 & 0.895 & 1.000 \\
Overall & 0.812 & 0.877 & 0.880 & & \\
\hline
\end{tabular}

These statistics are calculated prior to matching the distance measures to the PSID data. Hence they are not weighted to account for the prevalence of spousal pairings in occupation, i.e., the statistics treat all pairs as equally probable and attach equal weight. Our intention when reporting the measures of association is to show that each pair of measures is positively correlated and measures dissimilarity, but several pairs, such as Activities and Knowledge are far from perfectly correlated. Those two measures are capturing different dimensions of dissimilarity.

One of the primary challenges presented by household data is that some households have only one employed spouse. Consequently the distance between the spouses' occupations is not observed. It prompts the question: how far away from the employed spouse's occupation would the non-employed spouse's occupation be if they were to work? To address this problem, we attempt two separate fixes:

1. use the non-working spouse's first full time (adult) occupation in place of the current occupation when calculating distances, and

2. use the non-working spouse's first occupation to identify a probabilistic current occupation and measure distance based on the expected occupation.

Resolving the issue of single earner households is crucial because there is reason to believe that single earner households would match differently based on the underlying attributes proxied by occupations. The single earners are demonstrably specializing in labor market and home production-whereas the dual earners demonstrate shared consumption or productivity, as advanced by Clark \& Kanbur or Benham. It is conceivable that the former group sorts negatively (e.g., on wages) and the latter group sorts positively.

Of the 1427 single earner observations in the sample, we can estimate 1068 of their distance measures using the first full-time occupation for the non-working spouse, and we can estimate 1070 of them using the probabilistic approach (occupation with highest probability conditional on first full-time occupation). Though both methods yield similar probit results, number two is particularly attractive since it relies on revelations of the occupations that working spouses have joined and presumably non-working spouses would join. Number two is less direct in this regard, but it allows for the possibility of career progression in the interim between the first job and the present. The probabilistic occupation is the present occupation with the highest probability of selection, conditional on the individual's first full-time occupation. 


\section{Results}

\subsection{Dual earner households}

As a convenient point of departure, we present the results of the probit divorce model using the sample of married households for which we observe distance. The coefficient on "overall distance" between spouses' occupations is not significant in this model. However if the 4 constituent distance measures are included individually, two of them (activities and knowledge) have significant coefficients. We report these results on Table 3 in columns 1 and 2.

We report the marginal effects of the distance measures on Table 3 . They are calculated as the effect on the probability of dissolution (separation or divorce). These show that distance between activities of the spouses' jobs is bad for the match in terms of divorce. Distance between the required knowledge is good for the match in terms of fewer divorces. In the interest of brevity, the tables only contain the binary probit results, but we have also estimated them as ordered probits, binary logits and ordered logits, and the estimates are materially the same. An additional check we performed was splitting this sample into households with at least one (alternative: neither) college graduate spouse. The findings are robust to this; the primary distinction is that knowledge distance has a statistically stronger stabilizing effect for couples composed of at least one college graduate.

\subsection{Single earner households}

We next proceed to analyzing the results for single-earner households. Again looking at households where only one person works can provide an even cleaner test of the marital theories. Households have already revealed a preference for specializing in home and market work if only one works. Thus, any remaining influence of the

Table 3 Divorce model: dual earner households: marginal effects of distance measures

\begin{tabular}{lcc}
\hline & \multicolumn{2}{c}{ Probit } \\
\cline { 2 - 3 } Dependent variable: divorce (=1) & $\mathbf{1}$ & $\mathbf{2}$ \\
\hline Overall Distance & 0.0328 & - \\
Ability Distance & $-0.0266)$ & 0.1244 \\
Activities Distance & - & $(0.1040)$ \\
& - & $0.1623^{* *}$ \\
Skills Distance & - & $(0.0749)$ \\
& - & 0.0755 \\
Knowledge Distance & - & $(0.0895)$ \\
& - & $-0.1972^{* * *}$ \\
Household-Year Pairs & - & $(0.0617)$ \\
Includes Controls & 4141 & 4141 \\
Includes Occupation Indicators (Both Spouses) & Yes & Yes \\
Log Likelihood & Yes & Yes \\
Pseudo R Squared & -629.43 & -622.38 \\
\hline
\end{tabular}

${ }^{*} p<0.1 ;{ }^{* *} p<0.05 ;{ }^{* * *} p<0.01$. All standard errors are cluster robust. Marginal effects refer to the effect on the probability of dissolution $(y=1)$. In the interest of brevity, the coefficient estimates on other covariates are relegated to a table in the Additional file 1: Appendix. 
occupational distance measures for these households suggests inherent differences among spouses that might explain the strength of marriages.

The lack of current occupational information for one spouse, however, requires us to construct the distance measures from partial information. One strategy to deal with single earner households is to predict how far away from one another their occupations would be, conditional on their other characteristics. This would amount to an out-ofsample prediction of the distances ("distance hats") using information from the 2 earner sub-sample. Among the significant questions about the validity of such a procedure, it ignores any information contained in the working spouse's occupation. We observe the location of that spouse's occupation within the space, which should reveal something about the location of the other spouse's occupation. Some occupations are in densely populated parts of the space and are close to many other occupations, whereas others are remotely located within the space.

Our preferred strategy for treating single earner households estimates the occupation instead of the distance; then the distance is measured from the observed occupation to the synthetic one. The PSID contains the first full-time occupation of the respondents, and one could simply use that occupation in place of the unobserved current occupation. Estimates of the divorce model using this method are in Table 4. This result is consistent with the two earner sample in terms of the signs on the marginal effects, but the estimates are less precise. The single earner sample's estimates find a stronger destabilizing effect for activities distance, and it does not find the dual earner sample's stabilizing effect of knowledge distance.

The second and third columns on Table 4 allow for the likelihood that individuals travel along paths of occupations that are predictable based on their first full-time occupations. Identifying the occupation with the highest probability conditional on the first occupation

Table 4 Divorce model using first full-time occupation and probabilistic occupation for one earner households

\begin{tabular}{lccc}
\hline Dependent variable: divorce (=1) & $\mathbf{1}$ & $\mathbf{2}$ & $\mathbf{3}$ \\
\hline Ability Distance Marginal Effect & -0.3410 & -0.1388 & -0.0091 \\
& $(0.2112)$ & $(0.1818)$ & $(.1898)$ \\
Activities Distance Marginal Effect & 0.2332 & 0.1720 & 0.1844 \\
& $(0.1052)^{* *}$ & $(0.1101)$ & $(.1077)^{*}$ \\
Skills Distance Marginal Effect & 0.3506 & 0.0199 & -0.0475 \\
& $(0.1233)^{* * *}$ & $(0.1268)$ & $(.1103)$ \\
Knowledge Distance Marginal Effect & -0.0041 & -0.0866 & -0.1060 \\
& $(0.0982)$ & $(0.0898)$ & $(.0753)$ \\
Sample & 1 Earner Married & 1 Earner Married & 1 Earner Married \\
Missing Occupation & First Full Time & Probabilistic & Probabilistic \\
Household-Year Pairs & 1068 & 1070 & 1070 \\
Includes Controls & Yes & Yes & Yes \\
Includes Occupation Indicators & Yes & Yes & Yes; Interact with Indicator \\
(Both Spouses) & & for Employed (=1) \\
Log Likelihood & -113.76 & -120.68 & -118.10 \\
Pseudo R Squared & 0.3457 & 0.2930 & 0.3082 \\
\hline
\end{tabular}

${ }^{*} \mathrm{p}<0.1 ;{ }^{* *} \mathrm{p}<0.05 ;{ }^{* * *} \mathrm{p}<0.01$. Cluster (household) robust standard errors for the marginal effects in parentheses. A positive marginal effect signifies an increased probability of dissolution. 
lets us assign a distance measure that more closely resembles two spouses employed in the present period. Using the probabilistic occupation yields comparable estimates to the first full-time occupation; the marginal effects are similar except for the disappearance of the destabilizing effect of skills distance. Additionally the signs on the activities and knowledge effects match the signs from the two earner sample. But their precision is sensitive to whether or not the occupation indicators switch on for spouses that only probabilistically (not actually) work in the occupation (columns 2 and 3).

Finally we present the estimates on the pooled sample using these methods to address missing distances. Since this includes both types of households, we include an indicator for the single earner sub-sample. This indicator turns out to have a statistically insignificant effect on divorce probability, but it is reassuring to know that we control for differences, i.e., in marital attitudes or values, in the two sub-samples. We also interact that indicator with the four distance measures and test whether the effect of distance on marital stability differs for the two groups. We do not reject (far from it, actually) the null hypothesis that the effect is equal for both groups in the sample (Table 5). This test confirms the primary conclusion: regardless of whether both spouses work, similarities between their vocational activities stabilize the marriage, and similarities between their vocational knowledge destabilize the marriage. A full set of estimates is contained in a very large table in the Additional file 1: Appendix; it includes all of the explanatory variables from the models on Table 3 and Table 6 except for occupation indicators (because of their large number).

And the results hold if we restrict the sample to households in which neither spouse has changed his or her occupation since marriage (column 3, Table 6). This is gratifying

Table 5 Wald tests of differences by household type

\begin{tabular}{|c|c|c|c|c|}
\hline \multicolumn{2}{|c|}{ Divorce model interaction terms } & \multirow{2}{*}{$\frac{1}{0.1621^{* *}}$} & \multirow{2}{*}{$\frac{\mathbf{2}}{0.1740^{* *}}$} & \multirow{2}{*}{$\frac{3}{0.3400^{*}}$} \\
\hline Activities Distance & 2 Earner & & & \\
\hline & & $(.075)$ & $(.0749)$ & $(.1942)$ \\
\hline & 1 Earner & 0.1272 & $0.1965^{*}$ & $0.3869^{*}$ \\
\hline & & $(.1063)$ & $(.1132)$ & $(.221)$ \\
\hline & Chi Squared & 0.08 & 0.03 & 0.03 \\
\hline \multirow[t]{5}{*}{ Knowledge Distance } & 2 Earner & $-0.1857^{* * *}$ & $-0.2056^{* * *}$ & $-0.3389^{* *}$ \\
\hline & & $(.0605)$ & $(.0609)$ & $(.1527)$ \\
\hline & 1 Earner & -0.1441 & -0.1560 & -0.2957 \\
\hline & & $(.0937)$ & $(.091)$ & $(.2089)$ \\
\hline & Chi Squared & 0.15 & 0.23 & 0.03 \\
\hline \multicolumn{2}{|l|}{ Sample } & 1 and 2 Earners Pooled & 1 and 2 Earners Pooled & Pooled, Non-Changers \\
\hline \multicolumn{2}{|l|}{ Missing Occupation } & First Full Time & Probabilistic & Probabilistic \\
\hline \multicolumn{2}{|l|}{ Household-Year Pairs } & 5210 & 5212 & 1081 \\
\hline \multicolumn{2}{|l|}{ Includes Controls } & Yes & Yes & Yes \\
\hline \multicolumn{2}{|c|}{$\begin{array}{l}\text { Includes Occupation Indicators (Both } \\
\text { Spouses) }\end{array}$} & Yes & Yes & Yes \\
\hline \multicolumn{2}{|l|}{ Log Likelihood } & -769.71 & -770.96 & -190.09 \\
\hline \multicolumn{2}{|l|}{ Pseudo R Squared } & 0.1190 & 0.1145 & 0.1897 \\
\hline
\end{tabular}

This table shows the marginal effects of the two significant distance measures by household type (single and dual earners). A positive marginal effect signifies an increased probability of dissolution. Both columns are derived from the estimates on Table 6, estimating marginal effects for the two groups using group-specific covariate means. The Chi Squared statistic tests the null hypothesis that both groups' marginal effects are equal. Cluster (household) robust standard errors for the marginal effects in parentheses. The emphasis is on the non-significance of the Chi Squared statistics, which leads us to not reject the null hypothesis that distance has a common effect on marital stability for both types of households. 
because the findings are still apparent even excluding households that moved within the occupation space after marriage, possibly as a reaction to learning about their match quality.

\subsection{Discussion}

The empirical results state that knowing, or if necessary estimating from past occupations, two spouses' current occupations, helps predict whether their marriage will dissolve. Specifically more dissimilar occupations in terms of activities destabilize a marriage, and more dissimilar occupations in terms of knowledge stabilize a marriage. This finding is apparent among households with either one spouse or two spouses employed, as well as both groups pooled together. It is found consistently using multiple methods for estimating missing occupations in single earner households.

What do these dissimilarity measures mean for the several theories of marriage? An inference may be made by examining the descriptions of the O*Net variables in the appendix. As the broad categories suggest, activities consist of actions workers perform on their jobs, and knowledge consists of the content information needed to perform each job successfully. Occupation choices reflect one's preferences over the activities performed on the job and one's comparative advantage with respect to the knowledge required. A worker with a given set of knowledge can be expected to gravitate toward an occupation that entails performing relatively pleasurable activities. Similarly a worker with a given set of preferences over activities can be expected to choose an occupation at which he possesses masterful knowledge. Applying this interpretation to spouses' occupational distance measures, spouses who perform similar activities at

Table 6 Divorce model using probabilistic occupation for one earner households, pooled sample

\begin{tabular}{|c|c|c|c|}
\hline Dependent variable: divorce $(=1)$ & 1 & 2 & 3 \\
\hline \multirow[t]{2}{*}{ Ability Distance Marginal Effect } & 0.0641 & 0.0912 & $-0.4518^{*}$ \\
\hline & $(.0976)$ & $(.0947)$ & $(.2354)$ \\
\hline \multirow[t]{2}{*}{ Activities Distance Marginal Effect } & $0.1550^{* *}$ & $0.1787^{* * *}$ & $0.3518^{* *}$ \\
\hline & $(.0644)$ & $(.0649)$ & $(.156)$ \\
\hline \multirow[t]{2}{*}{ Skills Distance Marginal Effect } & 0.1059 & 0.0505 & $0.3797^{* *}$ \\
\hline & $(.0771)$ & $(.0791)$ & $(.1685)$ \\
\hline \multirow[t]{2}{*}{ Knowledge Distance Marginal Effect } & $-0.1772^{* * *}$ & $-0.1954^{* * *}$ & $-0.3280^{* * *}$ \\
\hline & $(.0533)$ & $(.0539)$ & $(.1279)$ \\
\hline Sample & $\begin{array}{l}1 \text { and } 2 \text { Earners } \\
\text { Pooled }\end{array}$ & $\begin{array}{l}1 \text { and } 2 \text { Earners } \\
\text { Pooled }\end{array}$ & $\begin{array}{l}\text { Pooled, Non- } \\
\text { Changers }\end{array}$ \\
\hline Missing Occupation & First Full Time & Probabilistic & Probabilistic \\
\hline Household-Year Pairs & 5210 & 5212 & 1081 \\
\hline Includes Controls & Yes & Yes & Yes \\
\hline $\begin{array}{l}\text { Includes Occupation Indicators (Both } \\
\text { Spouses) }\end{array}$ & Yes & Yes & Yes \\
\hline Log Likelihood & -769.71 & -770.96 & -190.09 \\
\hline Pseudo R Squared & 0.1190 & 0.1145 & 0.1897 \\
\hline
\end{tabular}

${ }^{*} p<0.1 ;{ }^{* *} p<0.05 ;{ }^{* * *} p<0.01$. Cluster (household) robust standard errors for the marginal effects in parentheses. A positive marginal effect signifies an increased probability of dissolution. The marginal effects are "grand margins". The group marginal effects are shown and tested for equality on the next table. "Non-changers" (column 3 ) refers to households in which neither spouse has changed occupations since marriage. 
work are treated as having similar preferences and spouses whose jobs require similar knowledge are treated as having similar comparative advantages. These interpretations therefore allow a way of testing the theories of marriage.

The effect of increased occupational distance on the probability of marital dissolution could have several explanations. First, they could reveal something about the earnings of the occupations that transcends the individuals' observed earnings, i.e., volatility, expectations, or correlation. Characteristics of one's occupational earnings profile enter the marital gains function separately from the effect of match quality. Second, occupations could reveal the values of spouses' options outside of marriage. Third, they could reveal match quality directly by capturing non-redundant household capital and overlapping preferences for household goods, as described in the preceding paragraph. This is the interpretation we endorse, considering that the estimates we present condition on the chosen occupations themselves, their earnings variance, and their covariance.

We separate the third explanation from the first and second by controlling for major occupation group effects from both spouses, i.e., indicators such as 1[husband's occupation is "Construction Trades"], and measures of both spouses' detailed occupations' time series earnings variance, as well as the covariance of earnings for their occupation pair. The effects of the distance measures persist, even with occupation and occupation pairspecific covariates, convincing us that they capture something about the match itself, and the risk of confusing them with insurance against earnings risks and marital opportunity costs is minimal. The obvious candidates for what they reveal about the match are the spouses' household comparative advantages and preference compatibility.

The stabilizing effect of similar activities supports theories of marriage predicated upon preferences for household (especially non-rival) goods. The results suggest that spouses are better matched when their preferences for activities overlap. We caution that preferences for work activities must be representative of preferences for goods to make this conclusion truly sound. Models of marriage based on non-rival household goods fit nicely with this result since they are particularly likely to be experiential in nature, e.g., leisure activities and spending time with children. Preferences for these non-rival household activities therefore would reasonably be assumed to be related to preferences for work activities. This is reflected strongly in our results as the results hold regardless of whether the spouses are currently working. Thus, preferences proxied by past occupational experiences do not yield notably different results than estimates using current occupation.

Models of marriage based on specialization gain support from our findings as well. Spouses with relatively distant (non-redundant) knowledge are less likely to divorce, even if both of them work instead of fully availing themselves of specialization. Notably knowledge distance is even more important to households in which both spouses work. The finding that non-redundant knowledge benefits dual earning couples, however, suggests that there is some household production that involves both spouses and increases with the diversity of the spouses' knowledge. A more subtle question (suggested by Lam (1988)) that is not answered is whether the stabilizing effect for single earners originates from home production of a non-rival household good or whether those goods are purchased à la Lam's preliminary (pp. 471-72) model. There is no clear support for a productivity-enhancing effect of spousal knowledge-at least not directly on divorce probability. If one spouse is benefiting from the knowledge of the other, the 
effect on marital stability must be operating indirectly through earnings-since similar knowledge means less stability in our model.

It is also interesting to note that occupational earnings covariance stabilizes a marriage. Its effect is same-signed and statistically significant in the two earner sample and the pooled sample. This could be because both occupations are trending upward (part of the reason their earnings are correlated) and the expected earnings growth increases marital gains. Other speculations are possible, as well, but at face value this evidence downplays occupational diversification as a method for combating earnings risk in a marriage. It leaves as a more plausible explanation that the different knowledge represented by the spouses' current occupation choices is complementary in providing household goods.

Finally the results of this paper speak to some of the issues raised by Lich-Tyler (2003) and Clark and Kanbur (2004), respectively. Specifically they show both the increasing importance of preference-based matching when incomes are higher and the increasing possibility of mismatch when household public goods are relatively more important. The first follows from a de-emphasis on home production in favor of purchasing household goods as incomes rise. Since the specialization motive for matching to a spouse becomes less pronounced, it becomes increasingly important to agree with one's spouse in terms of shared consumption preferences. The second comes from spousal sorting that emphasizes the distributions of tastes among the two sexes. If the distributions do not overlap sufficiently, the outer tails of the two groups get matched together in Clark and Kanbur's model, i.e., couples with opposing preferences. These heterogeneous couples are marginally matched and vulnerable to separation. A specification including an interaction between the distance measures and household income may illuminate the first question, and a version including measures of how idiosyncratic each spouse's job is may reveal the degree of preference mismatch.

\section{Conclusions}

When pop singer Paula Abdul and a cartoon cat depicting the male lead performed the song, "Opposites Attract" (1990), they were right and wrong about marriage. An idea as old as comparative advantage dictates that opposites attract in order to reap the greatest gains from specialization. Our findings confirm that spouses with dissimilar knowledge are better matched, other things equal. However, more usually the phrase refers to opposites on personal dimensions. In this paper those interpersonal sources of attraction are measured as dissimilarity of activities revealed through choice of occupation. In this context, opposite preferences for activities repel, other things equal.

Previous theoretical work by economists has predicted the findings in this paperthat similar preferences likely generate substantial marital gains, but specialization in disparate tasks generates marital gains as well. Taken as a whole, the results of this study empirically support each hypothesis. The reader should be cautioned that the credible interpretations of the two significant distance measures we advance are predicated on assumptions that knowledge and preferences over activities are revealed through occupation choice and that they translate into preferences and productive inputs for household goods. 


\section{Endnotes}

${ }^{1}$ And an expansive literature explores marital stability, as well as the related questions of spousal matching and gains from marriage. A complete review is beyond the scope of this paper, but a comprehensive review can be found in Lehrer (2003).

${ }^{2} \mathrm{~A}$ meta-analysis and review are in Sheu, et al. (2010).

${ }^{3} \mathrm{~A}$ summary of these is located online: http://www.onetcenter.org/dl_files/ContentModel_Detailed.pdf.

4"An occupation expert is a person who has several years of experience and training in an occupation. He or she has the expert knowledge required to respond to questions about the skills, knowledge and activities required for work in the occupation" (https:// onet.rti.org/faq_oe.cfm\#Q5).

${ }^{5}$ Though not reported in the paper, the results are also robust to a binary divorce variable in which all couples that separate or divorce are coded as "1" and only those that remain married and non-separated are coded as "0". The results, which we do not report in the paper, are comparable if the model is specified as an ordered probit (married, separated, divorce in that order) as well.

${ }^{6}$ The annual average real earnings are calculated for each occupation-year. They are expressed as natural logs, de-meaned (cross-sectionally), and then used to calculate variance (per occupation's time series) and covariance (per pair of occupations):

$$
\left.s^{2} \text { (occupation } i\right)=(T-1)^{-1} \sum_{t}\left(y_{i t}-\bar{y}_{i}\right)^{2} \text { and } s_{i j}=(T-1)^{-1} \sum_{t}\left(y_{i t}-\bar{y}_{i}\right)\left(y_{j t}-\bar{y}_{j}\right) .
$$

\section{Additional file}

Additional file 1: Appendix.

\section{Competing interests}

The IZA Journal of Labor Economics is committed to the IZA Guiding Principles of Research Integrity. The authors declare that they have observed these principles.

Responsible editor: Anne C. Gielen.

Author details

${ }^{1}$ Economics Department, Purdue University, 4043 W. State Street, Room 531, West Lafayette, IN 47907, USA.

${ }^{2}$ Department of Economics, UW-Milwaukee, 3210 N. Maryland Ave., Room 820, Milwaukee, WI 53211, USA.

Received: 24 June 2014 Accepted: 21 August 2014

Published: 08 Oct 2014

\section{References}

Becker G (1973) A theory of marriage: part I. J Polit Econ 81(4):813-846

Becker G (1974) A theory of marriage: part II. J Polit Econ 82(2):11-26

Benham L (1974) Benefits of women's education within marriage. J Polit Econ 82(2):57-71

Blackburn M (2003) The effects of the welfare system on marital dissolution. J Popul Econ 16(3):477-500

Boyle PJ, Kulu H, Cooke T, Gayle V, Mulder C (2008) Moving and union dissolution. Demography 45(1):209-222

Bramlett MD, Mosher WD (2002) Cohabitation, Marriage, Divorce and Re-Marriage in the United States. Division of Vital Statistics. National Center for Health Statistics, Hyattsville, MD

Bremmer D, Kesselring R (2004) Divorce and female labor force participation: evidence from time series data and cointegration. Atl Econ J 32:174-189

Charles K, Stephens MJ (2004) Job displacement disability and divorce. J Labor Econ 22(2):489-522

Clark S, Kanbur R (2004) Stable partnerships, matching, and local public goods. Eur Econ Rev 48(4):905-925

Ging LC, Kim NP (2011) The dynamics of divorce, income, and female labor force participation in Singapore. Econ Bull 31(4):2757-2768

Jensen P, Smith N (1990) Unemployment and marital dissolution. J Popul Econ 3(3):215-229

Johnson WR, Skinner J (1986) Labor supply and marital separation. Am Econ Rev 76(3):455-469 
Kalmijn M, Loeve A, Manting D (2007) Income dynamics in couples and the dissolution of marriage and cohabitation. Demography 44(1):159-179

King M, Ruggles SJ, Alexander JT, Flood S, Genadek K, Schroeder MB, Vick R (2012) Integrated Public Use Microdata Series, Current Population Survey: Version 3.0. Machine-readable database, Minneapolis, MN

Lam D (1988) Marriage markets and assortative mating with household public goods: theoretical results and empirical implications. J Hum Resour 23(3):462-487

Lehrer E (2008) Age at marriage and marital instability: revisiting the Becker-Landes-Michael hypothesis. J Popul Econ 21:463-484

Lehrer EL (2003) The economics of divorce. In: Marriage and the Economy: Theory and Evidence from Advanced Industrial Society. Cambridge University Press, Cambridge, pp 55-74

Leiber O, Composer (1990) Opposites Attract. [P. Abdul, Performer]

Lich-Tyler S (2003) Household Bargaining, the Marriage Market, and Assortative Matching Based on Preferences. Working Paper. Retrieved March 19, 2012, from http://www.unc.edu/ swlt/

Liu H, Lu J (2006) Measuring the degree of assortative mating. Econ Lett 92:317-322

McKinnish T (2007) Sexually integrated workplaces and divorce: another form of on the job search. J Hum Resour 42(2):331-352

O*Net. (n.d.) (2011) O*Net Database. Retrieved May 22, 2012, from http:/www.onetcenter.org/

Panel Study of Income Dynamics public use dataset (2003-2007). Ann Arbor, MI. Retrieved April 2012

Sheu H-B, Lent RW, Brown SD, Miller MJ, Hennessy KD, Duffy RD (2010) Testing the choice model of social cognitive career theory across Holland themes: a meta-analytic path analysis. J Vocat Behav 76(2):252-264

South S, Lloyd K (1995) Spousal alternatives and marital dissolution. Am Sociol Rev 60(1):21-35

Spitze G, South S (1985) Determinants of divorce over the marital life course. Am Sociol Rev 51:583-589

Tjotta S, Vaage K (2008) Public transfers and marital dissolution. J Popul Econ 21:419-437

Weiss Y (1997) The formation and dissolution of families: why marry? Who marries whom? And what happens upon

divorce. In: Rosenzweig M, Stark O (ed) The Handbook of Population and Family Economics, 1st edition, vol 1.

Elsevier Science, Amsterdam, pp 81-123

Weiss Y, Willis RJ (1997) Match quality, new information, and marital dissolution. J Labor Econ 15(1):293-329

10.1186/2193-8997-3-9

Cite this article as: Van Kammen and Adams: Dissimilar occupations and marital stability. IZA Journal of Labor Economics 2014, 3:9

\section{Submit your manuscript to a SpringerOpen ${ }^{\circ}$ journal and benefit from:}

- Convenient online submission

Rigorous peer review

- Immediate publication on acceptance

- Open access: articles freely available online

- High visibility within the field

- Retaining the copyright to your article

Submit your next manuscript at $\boldsymbol{~ s p r i n g e r o p e n . c o m ~}$ 